Jurnal Penelitian Perawat Profesional

Volume 3 Nomor 1, Februari 2021

e-ISSN 2715-6885; p-ISSN 2714-9757

http://jurnal.globalhealthsciencegroup.com/index.php/JPPP

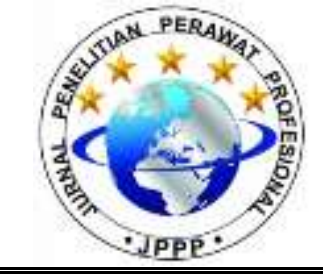

\title{
MANAJEMEN NYERI NEUROPATIK
}

Fryda Liana Devi

Fakultas Kedokteran, Universitas Lampung, Jl. Prof. DR. Ir. Sumatri Brojonegoro No.1, Gedong Meneng, Kec. Rajabasa, Kota Bandar Lampung, Lampung, Indonesia 35145

frydaliana00@gmail.com (+6285669234033)

\begin{abstract}
ABSTRAK
Diketahui jutaan orang di seluruh dunia telah mengalami nyeri neuropatik yang diperkirakan terjadi pada sebanyak 7\% dari populasi. Nyeri neuropatik merupakan salah satu jenis nyeri yang timbul akibat adanya lesi atau gangguan primer pada susunan saraf. Nyeri ini dapat terjadi akibat berbagai gangguan, seperti penyakit infeksi, trauma, radikulopati dan kerusakan di sistem endokrin. Tujuan dari literature review iniadalah untuk meninjau lebih lanjut terkait masalah nyeri neuropatik yang umum terjadi sehingga dapat diketahui langkah manajemen masalah ini dengan tepatdi masyarakat.Metode. Penelitian ini merupakan studi literature review yang melibatkan sebanyak 21 sumber pustaka. Kata kunci yang digunakan dalam penelusuran yaitu 'neuropathic pain dan management dengan tahun terbit antara 2009-2020. Abstrak dan full text jurnal dibaca dan dicermati, kemudian dilakukan analisis terhadap isi yang terdapat dalam tujuan penelitian dan hasil/temuan penelitian. Hasil. Berbagai penelitian menunjukkan farmakoterapi sering kali merupakan salah satu langkah yang efektif yang dapat dengan cepat memberikan dasar untuk implementasi komponen lain dari manajemen nyeri, seperti modalitas terapi fisik dan keterampilan koping pasien.Pendekatan multidisiplin dan multimodal dalam manajemen nyeri neuropati dapat meredakan derajat nyeri untuk sebagian besar pasien yang menderita nyeri neuropati. Beberapa jenis obat yang direkomendasikan dalam pengobatan nyeri neuropatik, antara lain golongan obat anti-depresan, antikonvulsan, obat topikal dan golongan analgetik.
\end{abstract}

Kata kunci: manajemen; nyeri neuropatik

\section{NEUROPATHIC PAIN MANAGEMENT}

\begin{abstract}
It is known that millions of people around the world have experienced neuropathic pain which is estimated to occur in as many as 7\% of the population. Neuropathic pain is a type of pain that arises from a primary lesion or disturbance in the nervous system. This pain can occur due to various disorders, such as infectious diseases, trauma, radiculopathy and damage to the endocrine system. The purpose of this literature review is to further review the common neuropathic pain problems so that the appropriate steps for managing this problem can be identified in the community. Method. This research is a literature review study involving 21 literature sources. The keywords used in the search were "neuropathic pain and management" with the publication year between 2009-2020. The abstract and full text of the journal are read and examined, then an analysis is carried out of the contents contained in the research objectives and the results / research findings. Result. Studies have shown that pharmacotherapy is often an effective measure that can quickly provide a basis for implementing other components of pain management, such as physical therapy modalities and patient coping skills. Multidisciplinary and multimodal approaches to the management of neuropathic pain can relieve pain levels for the majority of patients suffering from neuropathic pain. Several types of drugs recommended in the treatment of neuropathic pain include anti-depressants, anticonvulsants, topical drugs and analgesics.
\end{abstract}


Keywords: management; neuropathic pain

\section{PENDAHULUAN}

Sistem somatosensori memungkinkan adanya persepsi sentuhan, tekanan, nyeri, suhu, posisi, gerakan, dan getaran. Saraf somatosensori ditemukan di kulit, otot, persendian dan fasia dan termasuk termoreseptor, mekanoreseptor, kemoreseptor, prurikeptor dan nosiseptor yang mengirim sinyal ke sumsum tulang belakang dan akhirnya ke otak untuk diproses lebih lanjut. Kebanyakan proses sensorik melibatkan nukleus thalamus yang menerima sinyal sensorik yang kemudian diarahkan ke korteks serebral. Lesi atau penyakit pada sistem saraf somatosensori dapat menyebabkan transmisi sinyal sensorik yang berubah dan tidak teratur ke sumsum tulang belakang dan otak (Colloca et al., 2017).

Nyeri neuropatik didefinisikan sebagai nyeri yang berhubungan dengan lesi atau penyakit pada sistem saraf somatosensori, yang dapat terjadi akibat pembedahan dan berbagai kondisi, termasuk diabetes, infeksi herpes zoster, stroke, multiple sclerosis, dan lesi medula spinalis (Attal et al., 2018). Nyeri neuropatik merupakan masalah umum dalam praktik klinis. Persisnya seberapa umum nyeri neuropatik dapat sulit untuk diukur karena terdapat masalah dengan bagaimana mendefinisikan dan menilai nyeri neuropatik, tetapi prevalensi pada populasi umum diperkirakan antara $7 \%$ dan 10\% (Van Hecke et al., 2014). Di Amerika Serikat, nyeri neuropati perifer diabetik yang menyakitkan mempengaruhi sekitar 10 juta orang. Diperkirakan sepertiga dari pasien dengan diabetes mellitus memiliki neuropati diabetik yang menyakitkan, dan pada tahun 2014 Centers for
Disease Control (CDC) memperkirakan bahwa 30 juta orang di Amerika Serikat menderita diabetes mellitus dimana jumlah ini akan terus meningkat (Zilliox, 2017).

Nyeri neuropatik secara mekanis tidak serupa dengan kondisi nyeri kronis lainnya seperti nyeri inflamasi, misalnya pada rheumatoid arthritis, di mana penyebab utamanya adalah inflamasi dengan peristiwa kimiawi yang terjadi di tempat inflamasi, dan nyeri seperti itu didiagnosis dan dirawat secara berbeda (Costigan et al., 2009). Nyeri neuropatik juga dikaitkan dengan peningkatan resep obat dan kunjungan ke penyedia layanan kesehatan (Colloca et al., 2017). Pasien biasanya mengalami serangkaian gejala yang berbeda, seperti sensasi terbakar dan tersengat listrik, dan nyeri akibat rangsangan yang tidak menyakitkan (seperti sentuhan ringan); gejalanya menetap dan cenderung menjadi kronis dan kurang merespons obat pereda nyeri. Gangguan tidur, kecemasan dan depresi sering terjadi dan parah pada pasien dengan nyeri neuropatik, dan kualitas hidup lebih terganggu pada pasien dengan nyeri neuropatik kronis dibandingkan pada pasien dengan nyeri non-neuropatik kronis yang tidak berasal dari saraf yang rusak atau teriritasi (Finnerup et al., 2016).

Neuropati perifer juga merupakan salah satu komplikasi mikrovaskuler yang paling umum dan dapat berkembang hingga $50 \%$ dari pasien diabetes. Neuropati perifer diabetik bermanifestasi dalam gejala klinis yang berbeda, termasuk paresthesia, dysesthesia, perubahan rasa getaran dan propriosepsi, refleks tendon dalam hipoaktif, kelemahan motorik, dan nyeri 
neuropatik. (Gok Metin et al., 2017). Nyeri neuropatik mungkin merupakan salah satu gejala yang paling umum dan mengganggu pada pasien dengan neuropati perifer diabetik. Studi mengungkapkan bahwa $16 \%$ hingga $26 \%$ pasien dengan neuropati perifer diabetik menderita nyeri (Abbott et al., 2011). Studi yang relevan telah menunjukkan bahwa nyeri neuropatik dapat mempengaruhi kualitas hidup (Quality of Lifel QoL), membatasi aktivitas kehidupan sehari-hari, keterampilan perawatan diri, pekerjaan, kualitas tidur, dan hubungan interpersonal (Motilal \& Maharaj, 2013).

Selain neuropatiperi ferdiabetik yang menyakitkan, kondisi nyeri neuropatik lain yang sering terlihat oleh ahli saraf antara lain nyeri neuropati non diabetes, neuralgia postherpetik, neuralgia trigeminal, radikulopati dan sindromoperasi punggung yang gagal, nyeri pasca stroke sentral, cedera sumsum tulang belakang, dan multiple sclerosis (Zilliox, 2017).

Penatalaksanaan nyeri neuropatik merupakan kebutuhan medis yang sebagian besar tidak teratasi. Di masa lalu, nyeri neuropatik tidak selalu dikenali oleh dokter, dan sering kali ditangani atau diobati dengan tidak tepat. Namun, pengembangan kuesioner sederhana khusus untuk nyeri neuropatik yang pada dasarnya didasarkan pada pelaporan diri secara verbal dari aspek kualitatif nyeri dapat memperbaiki diagnosis dan manajemen nyeri neuropati dalam decade terakhir (Attal et al., 2018). Oleh karena itu literature review ini bertujuan untuk meninjau lebih lanjut terkait masalah nyeri neuropatik yang umum terjadi di masyarakat sehingga dapat diketahui langkah manajemen masalah ini dengan tepat.

\section{METODE}

Penelitian ini merupakan studi literature review, yang menyajikan kembali materi yang diterbitkan sebelumnya, dan melaporkan fakta atau analisis baru. Penelusuran sumber pustaka dalam artikel ini melalui database PubMed dan Google Scholar. Sumber pustaka yang digunakan dalam penyusunan melibatkan 21 pustaka dengan kata kunci yang digunakan dalam penelusuran antara lain 'neuropathic pain dan management' dengan tahun terbit antara 2009-2020. Pemilihan artikel sumber pustaka dilakukan dengan melakukan peninjauan pada judul, abstrak dan hasil yang membahas manajemen nyeri neuropati. Abstrak dan full text jurnal dibaca dan dicermati, kemudian dilakukan analisis terhadap isi yang terdapat dalam tujuan penelitian dan hasil/temuan penelitian. Dilakukan koding terhadap isi jurnal yang direview berdasarkan garis besar atau inti dari penelitian tersebut yang dilakukan dengan mengurai dalam sebuah kalimat, dan jika sudah terkumpul kemudian dicari persamaan dan perbedaan pada masing-masing penelitian lalu dibahas untuk menarik kesimpulan.

\section{HASIL}

Gabapentin dengan dosis $1800 \mathrm{mg}$ sampai $3600 \mathrm{mg}$ setiap hari (1200-3600 $\mathrm{mg}$ gabapentin encarbil) dapat memberikan efek pereda nyeri yang baik untuk beberapa orang dengan neuralgia postherpetic dan neuropati diabetik perifer. Hasil dari setidaknya $50 \%$ pengurangan intensitas nyeri dianggap sebagai hasil pengobatan yang efektif oleh pasien, dan pencapaian tingkat pengurangan nyeri ini dikaitkan dengan efek menguntungkan yang penting pada gangguan tidur, kelelahan, dan depresi, serta kualitas hidup, fungsi, 
dan pekerjaan. Sekitar 3 atau 4 dari 10 peserta mencapai efek pereda nyeri ini dengan gabapentin, dibandingkan dengan 1 atau 2 dari 10 peserta pada plasebo (Moore et al., 2014).

Sementara dalam penelitian Tanenberg et al (2011) menunjukkan bahwa pengobatan dengan duloxetine, $60 \mathrm{mg}$ sekali sehari, tidak kalah dengan pregabalin, $300 \mathrm{mg} /$ hari, pada pasien dengan neuropati perifer diabetik yang memiliki respon nyeri suboptimal terhadap gabapentin. Penambahan duloxetine ke gabapentin bersifat efektif, yaitu pasien mengalami pengurangan rasa sakit yang serupa dengan yang dicapai dengan monoterapi duloxetine atau pregabalin.

Besarnya pengurangan nyeri yang diamati dalam penelitian ini, termasuk pasien dengan kondisi nyeri komorbid, konsisten dengan laporan dari uji klinis duloxetine dan pregabalin dari duloxetine dan pregabalin yang terkontrol plasebo pada pasien tanpa kondisi komorbid ini. Perubahan ratarata dalam tingkat nyeri pada endpoint adalah -2,6 untuk duloxetine dan -2,1 untuk pregabalin. Mengenai efek samping, mual, insomnia, hiperhidrosis, dan penurunan nafsu makan lebih sering terjadi dengan duloxetine daripada pregabalin; insomnia, lebih sering dengan duloxetine dibandingkan duloxetine plus gabapentin; edema perifer, lebih sering dengan pregabalin dibandingkan dengan duloxetine; dan mual, hiperhidrosis, nafsu makan menurun, dan muntah, lebih sering dengan duloxetine plus gabapentin dibandingkan dengan pregabalin(Tanenberg et al., 2011).

Penelitian lain dilakukan oleh Gok Metin et al (2017) dengan sampel penelitian terdiri dari 46 pasien, yang secara acak dialokasikan ke kelompok intervensi $(\mathrm{n}=21)$ dan kelompok kontrol $(n=25)$. Kelompok intervensi menerima pijat aromaterapi tiga kali seminggu selama 4 minggu. Kelompok kontrol hanya menerima perawatan rutin. Data dikumpulkan dari pasien dengan menggunakan kuesioner Douleur Neuropathique, skala analog visual, dan kuesioner Neuropathic Pain Impact on Quality of Life. Didapatkan skor nyeri neuropatik menurun secara signifikan pada kelompok intervensi dibandingkan dengan kelompok kontrol pada minggu keempat penelitian. Demikian pula, skor kualitas hidup meningkat secara signifikan pada kelompok intervensi pada minggu keempat penelitian. Sehingga dapat disimpulkan bahwa pijat aromaterapi adalah intervensi keperawatan nonfarmakologis yang sederhana dan efektif yang dapat digunakan untuk mengatasi nyeri neuropatik dan meningkatkan kualitas hidup pada pasien dengan nyeri neuropati (Gok Metin et al., 2017).

\section{PEMBAHASAN}

The International Association for the Study of Pain (IASP), mendefinisikan nyeri neuropatik sebagai nyeri yang disebabkan oleh lesi atau penyakit pada sistem saraf somatosensori. (Jones et al., 2016). Definisi ini berarti bahwa adanya tanda atau gejala saja tidak cukup untuk mendiagnosis nyeri neuropatik, tetapi pertimbangan klinis sering dibutuhkan. Nyeri neuropatik sering diklasifikasikan sebagai nyeri sentral atau perifer, bergantung pada lokasi lesi yang menyebabkan nyeri. Namun, nyeri neuropatik dapat dianggap sebagai manifestasi dari beberapa proses sistem saraf perifer dan pusat yang mengakibatkan sensitisasi sistem saraf perifer dan pusat. Seiring berkembangnya pengetahuan tentang patofisiologi yang mendasari nyeri 
neuropatik, tersedia beberapa target pengobatan yang berbeda namun tetap berfokus untuk mengidentifikasi mekanisme utama pada individu tertentu dan menargetkannya dengan tepat. Dalam praktiknya, beberapa mekanisme berbeda dapat muncul bersamaan dan berubah seiring waktu, dan respons individu terhadap pengobatan tetap tidak dapat diprediksi. Dalam sistem saraf tepi, pertumbuhan baru dari saraf yang cedera akan muncul secara spontan (pelepasan ektopik), dan akhirnya hubungan antar neuron mungkin berkembang di antara area baru pertumbuhan ini dan neuron aferen di dekatnya. Dengan cara ini nyeri neuropatik dapat dihasilkan baik dari cedera atau neuron sensorik yang utuh. Kerusakan pada saraf juga menyebabkan peningkatan jumlah saluran natrium dan kalsium yang ada. Penyebab lain dari sensitisasi perifer juga termasuk peningkatan responsivitas terhadap mediator inflamasi yang dilepaskan oleh sel yang rusak dan pertumbuhan neuron simpatis di ganglion akar dorsal. Sensitisasi sentral mengacu pada peningkatan eksitasi dan pengurangan penghambatan jalur sistem saraf pusat yang berhubungan dengan nyeri neuropatik. Input berulang dari serat $\mathrm{C}$ perifer menghasilkan peningkatan rangsangan medula spinalis. Selain itu, cedera pada struktur sistem saraf pusat dapat mengubah proses sensorik (Zilliox, 2017).

Tidak terdapat tes diagnostik tunggal atau gejala patognomonik untuk mengidentifikasi nyeri neuropatik. Faktanya, kebanyakan pasien dengan nyeri neuropatik biasanya memiliki berbagai jenis nyeri yang muncul bersamaan. Hal ini menunjukkan bahwa riwayat yang cermat dan pemeriksaan fisik menjadi sangat penting pada pasien yang sedang dievaluasi untuk nyeri neuropatik (Finnerup et al., 2015). Penggunaan tes diagnostik secara rutin juga tidak diperlukan untuk identifikasi nyeri neuropatik pada pasien (Haanpää et al., 2011). Bahkan jika terdapat riwayat ambigu atau pemeriksaan fisik yang belum tentu jelas, penentuan dugaan nyeri sebagai neuropatik seringkali dapat dianggap tepat dan pengobatan dapat dimulai. Pengujian diagnostik sangat berharga untuk mengidentifikasi penyebab yang mendasari nyeri neuropatik jika penyebabnya tidak diketahui. Pengujian dapat mencakup studi laboratorium untuk menilai gangguan elektrolit atau studi pencitraan, seperti radiograf, CT, atau MRI, untuk mengidentifikasi lesi struktural. Elektromiografi dan studi konduksi saraf juga dapat membantu untuk menentukan adanya fungsi neuromuskuler yang abnormal dan memperjelas lokasi gangguan. Keputusan untuk dalam memillih pengujian diagnostik dan tes bervariasi berdasarkan pada diagnosis banding untuk setiap pasien. Perlu ditekankan bahwa tidak satu pun dari tes tersebut yang memverifikasi ada atau tidaknya nyeri tetapi berfungsi untuk mengungkap penyebab potensial gejala mereka (Jones et al., 2016).

Terdapat alat skrining seperti Skala Nyeri Neuropatik dan Kuesioner Nyeri Neuropatik, yang tersedia khusus untuk pasien dengan nyeri neuropatik. Namun, penilaian klinis yang cermat masih diperlukan karena alat skrining ini dapat gagal mengidentifikasi $10 \%$ hingga $20 \%$ pasien dengan nyeri neuropatik (Cruccu et al., 2010). Dalam kasus nyeri neuropatik kronis, penting untuk memasukkan penilaian komorbiditas psikologis, gangguan tidur, pekerjaanmasalah terkait, harapan pengobatan, dan ketersediaan dukungan sosial. 


$\begin{array}{ll}\text { Kadang-kadang, kondisi seperti } & \text { hingga 50\% dan hanya pada } \\ \text { kecemasan atau depresi rapat } & \begin{array}{l}\text { subkelompok pasien, paling sering } \\ \text { untuk sekitar 40\% pasien (Dworkin et }\end{array} \\ \text { menyebabkan respons yang berlebihan } & \begin{array}{l}\text { al, 2011). Karena obat-obatan individu } \\ \text { terhadap rasa sakit, tetapi penting untuk }\end{array} \\ \text { berkomunikasi secara jelas dengan } & \text { memiliki manfaat yang terbatas, obat- } \\ \text { pasien, memvalidasi pengalaman } & \text { obatan sering digabungkan dalam terapi } \\ \text { mereka dengan rasa sakit, dan } & \text { untuk meningkatkan hasil yang diikuti } \\ \text { menetapkan tujuan pengobatan yang } & \text { dengan implementasi modalitas lainnya } \\ \text { realistis (Zilliox, 2017) } & \text { (Gilron et al., 2013). Pendekatan } \\ \text { Kuesioner standar untuk karakterisasi } & \text { seimbang yang mencakup berbagai } \\ \text { nyeri harus digunakan dalam diagnosis } & \text { pengobatan dan perawatan } \\ \text { nyeri neuropatik dari setiap etiologi. Hal } & \text { nonfarmakologis harus diantisipasi } \\ \text { ini dapat memberikan gambaran yang } & \text { sejak awal sebagai bagian dari } \\ \text { baik tentang persepsi nyeri subjektif dan } & \text { perencanaan pengobatan (Jones et al., } \\ \text { komponen psikososial nyeri sebagai } & \text { 2016). Tujuan terapi realistis untuk } \\ \text { suplemen untuk diagnosis klinis, tetapi } & \text { nyeri neuropatik adalah pengurangan } \\ \text { tanpa pemeriksaan klinis kuesioner ini } & \text { nyeri } \geq 30 \% \text {, peningkatan kualitas tidur, } \\ \text { tidak cocok sebagai satu-satunya cara } & \text { peningkatan kualitas hidup, pelestarian } \\ \text { untuk mendiagnosis nyeri neuropatik. } & \text { aktivitas dan hubungan sosial, } \\ \text { Dasar diagnosis lebih lanjut adalah } & \text { mempertahankan kemampuan kerja, dan } \\ \text { pemeriksaan neurologis lengkap. } & \text { peningkatan fungsionalitas (Schlereth, } \\ \text { Pemeriksaan berbasis peralatan lebih } & \text { 2020). }\end{array}$
lanjut (somatosensory evoked potentials, neurografi, metode pencitraan seperti MRI atau CT), pemeriksaan laboratorium atau cairan cerebrospinal harus dilakukan tergantung pada riwayat medis pasien dan temuan klinis. Untuk detailnya mengacu pada pedoman diagnosis untuk penyakit yang berkaitan (Schlereth, 2020).

Farmakoterapi sering kali merupakan salah satu langkah pertama dalam pengobatan nyeri karena kesederhanaan dan kemudahan pemberiannya. Jika efektif, farmakoterapi dapat dengan cepat memberikan dasar untuk implementasi komponen lain dari manajemen nyeri, seperti modalitas terapi fisik dan keterampilan koping. Sayangnya, bahkan obat yang disetujui untuk pengobatan nyeri neuropatik hanya memberikan pereda nyeri parsial. Pengobatan terbukti paling efektif untuk mengelola nyeri neuropati paling sering hanya memberikan perbaikan $30 \%$
Terdapat beberapa jenis obat yang direkomendasikan dalam pengobatan nyeri neuropatik, antara lain golongan obat anti-depresan, antikonvulsan, obat topikal dan golongan analgetik.Berdasarkan rekomendasi IASP untuk evidance based medicine pada kasus nyeri neuropatik, pilihan terapi yang digunakan dibagi menjadi pengobatan lini I, lini II, dan lini III. Pada lini pertama, obat yang digunakan antara lain tricyclic antidepressants (TCAs), serotonin and norepinephrine reuptake inhibitor (SNRI), calcium channel bloker $\alpha 2 \delta \quad$ (gabapentin, Obat lini kedua terdiri dari golongan Opioid, dan pada lini ketiga terdiri dari golongan anti konvulsan lainnya dan golongan anti depressan lainnya (Rakhmawati Emril et al., 2018). Pendekatan terapi nyeri neuropatik yang rasional adalah berdasarkan mekanisme terjadinya nyeri neuropatik. Manajemen nyeri neuropatik kronik idealnya pregabalin) dan lidokain topikal $5 \%$. 
dilakukan secara multidisiplin dan berdasarkan guideline dengan memperhatikan untung dan ruginya. Semua organisasi Internasional merekomendasikan pregabalin sebagai obat lini pertama untuk terapi farmakologi hampir semua nyeri neuropati, kecuali untuk neuralgia trigeminal obat lini pertama adalah karbamasepin dan okskarbasepin (Purwata et al., 2016). Terapi harus dimulai dari obat lini pertama, jika efektivitas tidak memuaskan atau terjadi efek samping, maka dapat diberikan obat kombinasi dari kelas obat lain. Jika efeknya masih tidak memuaskan, lini kedua atau obat lini ketiga dapat digunakan, baik sendiri atau dikombinasi, disesuaikan dengan kebutuhan pasien (Rakhmawati Emril et al., 2018).

Sementara itu, pasien diabetes mellitus umumnya dikaitkan dengan neuropati perifer, yang meliputi sensasi nyeri pada ekstremitas yang digambarkan sebagai nyeri, terbakar, menusuk, atau kesemutan. Nyeri yang terkait dengan neuropati perifer diabetik mungkin sebagian disebabkan karena kegagalan mekanisme analgesik endogen di jaras spinal desenden yang mengontrol transmisi nyeri ke otak. Secara historis, nyeri neuropatik perifer diabetik juga telah diobati dengan antidepresan trisiklik (TCA), analgesik opioid, dan agen antikonvulsan tertentu. Meskipun TCA telah menjadi pengobatan standar untuk neuropati perifer diabetik, penggunaan jangka panjang dapat dikaitkan dengan efek samping yang serius seperti hipotensi ortostatik, risiko efek samping kardiovaskular yang lebih besar, dan kematian. Analgesik opioid memberikan pereda nyeri yang cepat, tetapi efek samping dan potensi penyalahgunaan atau kecanduan membuat pilihan ini kurang diinginkan untuk pengobatan jangka panjang. Di antara agen antikonvulsan, gabapentin adalah obat yang biasa diresepkan untuk pengelolaan neuropati perifer diabetic. Obat ini dianggap memiliki profil keamanan yang umumnya tanpa interaksi obat yang penting secara klinis tetapi mungkin memerlukan beberapa minggu untuk mencapai dosis yang efektif (1800-3600 mg / hari). Dan saat ini, 2 obat disetujui oleh Food and Drug Administration AS untuk pengelolaan neuropati perifer diabetik, yaitu duloxetine hydrochloride dan pregabalin. Mekanisme kerja yang diusulkan dari duloxetine, antidepresan, adalah penghambatan reuptake serotonin dan norepinefrin di sistem saraf pusat, yang meningkatkan aktivitas neurotransmiter ini dan kemudian mengurangi persepsi nyeri dengan memodulasi sinyal nyeri. Sebaliknya, pregabalin, agen antikonvulsan, memiliki mekanisme aksi analgesik yang diusulkan yang melibatkan pengikatan pada subunit saluran kalsium $\alpha 2-\delta$ di neuron aferen hipereksit, yang mengurangi pelepasan glutamat, norepinefrin, dan substansi $\mathrm{P}$, sehingga mengurangi sinyal nyeri yang ditransmisikan dari perifer ke otak (Tanenberg et al., 2011).

\section{SIMPULAN}

Nyeri neuropatik merupakan salah satu jenis nyeri yang timbul akibat adanya lesi atau gangguan primer pada susunan saraf. Nyeri ini dapat terjadi akibat berbagai gangguan, seperti penyakit infeksi, trauma, radikulopati dan kerusakan di sistem endokrin. Nyeri neuropatik bersifat kompleks dan dinamis dalam presentasi dan mekanisme yang mendasarinya. Meskipun kompleksitas ini masih belum dipahami secara sepenuhnya, prinsip modern dari pendekatan multidisiplin dan multimodal masih 
dapat dan benar-benar meredakan derajat nyeri untuk sebagian besar pasien yang menderita nyeri neuropati. Beberapa jenis obat yang direkomendasikan dalam pengobatan nyeri neuropatik, antara lain golongan obat anti-depresan, antikonvulsan, obat topikal dan golongan analgetik.

\section{DAFTAR PUSTAKA}

Abbott, C. A., Malik, R. A., Van Ross, E. R. E., Kulkarni, J., \& Boulton, A. J. M. (2011). Prevalence and characteristics of painful diabetic neuropathy in a large communitybased diabetic population in the U.K. Diabetes Care, 34(10), 2220-2224.

https://doi.org/10.2337/dc11-1108

Attal, N., Bouhassira, D., \& Baron, R. (2018). Diagnosis and assessment of neuropathic pain through questionnaires. The Lancet Neurology, 17(5), 456-466. https://doi.org/10.1016/S14744422(18)30071-1

Colloca, L., Ludman, T., Bouhassira, D., Baron, R., Dickenson, A. H., Yarnitsky, D., Freeman, R., Truini, A., Attal, N., Finnerup, N. B., Eccleston, C., Kalso, E., Bennett, D. L., Dworkin, R. H., \& Raja, S. N. (2017). Neuropathic pain. Nature Reviews Disease Primers, 3, 1-20. https://doi.org/10.1038/nrdp.2017. 2

Costigan, M., Scholz, J., \& Woolf, C. J. (2009). Neuropathic Pain: A Maladaptive Response of the Nervous System to Damage. Annu Rev Neurosci, 32, 1-32. https://doi.org/10.1146/annurev.ne uro.051508.135531.Neuropathic

Cruccu, G., Sommer, C., Anand, P.,
Attal, N., Baron, R., GarciaLarrea, L., Haanpaa, M., Jensen, T. S., Serra, J., \& Treede, R. D. (2010). EFNS guidelines on neuropathic pain assessment: Revised 2009. European Journal of Neurology, 17(8), 1010-1018. https://doi.org/10.1111/j.14681331.2010.02969.x

Dworkin, R. H., Jensen, M. P., Gould, E., Jones, B. A., Xiang, Q., Galer, B. S., \& Gammaitoni, A. R. (2011). Treatment satisfaction in osteoarthritis and chronic low back pain: The role of pain, physical and emotional functioning, sleep, and adverse events. Journal of Pain, 12(4), 416-424.

https://doi.org/10.1016/j.jpain.201 0.07 .009

Finnerup, N. B., Attal, N., Haroutounian, S., McNicol, E., Baron, R., Dworkin, R. H., Gilron, I., Haanpää, M., Hansson, P., Jensen, T. S., Kamerman, P. R., Lund, K., Moore, A., Raja, S. N., Rice, A. S. C., Rowbotham, M., Sena, E., Siddall, P., Smith, B. H., \& Wallace, M. (2015). Pharmacotherapy for neuropathic pain in adults: A systematic review and meta-analysis. The Lancet Neurology, 14(2), 162173.

https://doi.org/10.1016/S14744422(14)70251-0

Finnerup, N. B., Haroutounian, S., Kamerman, P., Baron, R., Bennett, D. L. H., Bouhassira, D., Cruccu, G., Freeman, R., Hansson, P., Nurmikko, T., Raja, S. N., Rice, A. S. C., Serra, J., Smith, B. H., Treede, R. D., \& Jensen, T. S. (2016). Neuropathic pain: An updated grading system 
for research and clinical practice. Pain, 157(8), 1599-1606. https://doi.org/10.1097/j.pain.000 0000000000492

Gilron, I., Jensen, T. S., \& Dickenson, A. H. (2013). Combination pharmacotherapy for management of chronic pain: From bench to bedside. The Lancet Neurology, 12(11), 1084-1095. https://doi.org/10.1016/S14744422(13)70193-5

Gok Metin, Z., Arikan Donmez, A., Izgu, N., Ozdemir, L., \& Arslan, I. E. (2017). Aromatherapy Massage for Neuropathic Pain and Quality of Life in Diabetic Patients. Journal of Nursing Scholarship, 49(4), 379-388. https://doi.org/10.1111/jnu.12300

Haanpää, M., Attal, N., Backonja, M., Baron, R., Bennett, M., Bouhassira, D., Cruccu, G., Hansson, P., Haythornthwaite, J. A., Iannetti, G. D., Jensen, T. S., Kauppila, T., Nurmikko, T. J., Rice, A. S. C., Rowbotham, M., Serra, J., Sommer, C., Smith, B. H., \& Treede, R. D. (2011). NeuPSIG guidelines on neuropathic pain assessment. Pain, 152(1), 14-27. https://doi.org/10.1016/j.pain.201 0.07 .031

Jones, R. C. W., Lawson, E., \& Backonja, M. (2016). Managing Neuropathic Pain. Medical Clinics of North America, 100(1), 151167.

https://doi.org/10.1016/j.mcna.20 15.08.009

Moore, R. A., Wiffen, P. J., Derry, S., \& Rice, A. S. C. (2014). Gabapentin for chronic neuropathic pain and fibromyalgia in adults. Cochrane Database of Systematic Reviews, 2017(3). https://doi.org/10.1002/14651858. CD007938.pub3

Motilal, S., \& Maharaj, R. G. (2013). Nutmeg extracts for painful diabetic neuropathy: A randomized, double-blind, controlled study. Journal of Alternative and Complementary Medicine, 19(4), 347-352. https://doi.org/10.1089/acm.2012. 0016

Purwata, T. E., Widyadharma, P. E., \& Wijayanti, I. A. S. (2016). Management of Neuropathic Pain in Elderly Focus on Pregabalin. 4TH BALI NEUROLOGY UPDATE, 1-11. https://doi.org/10.1212/CON.0000 000000000928

Rakhmawati Emril, D., Akramah Basar, A., Kurniawan, H., Neurologi Kedokteran Universitas Syiah Kuala Banda Aceh, B., \& Patologi Klinik Fakultas Kedokteran Universitas Syiah Kuala Banda Aceh, B. (2018). The Pattern of Neuropathic Pain Management At Primary Health Care in Banda Aceh. Jurnal Sinaps, 1(3), 78-91.

Schlereth, T. (2020). Guideline "diagnosis and non interventional therapy of neuropathic pain" of the German Society of Neurology (deutsche Gesellschaft für Neurologie). Neurological Research and Practice, 2(1). https://doi.org/10.1186/s42466020-00063-3

Tanenberg, R. J., Irving, G. A., Risser, R. C., Ahl, J., Robinson, M. J., Skljarevski, V., \& Malcolm, S. K. (2011). Duloxetine, pregabalin, and duloxetine plus gabapentin 
for diabetic peripheral neuropathic pain management in patients with inadequate pain response to gabapentin: An open-label, randomized, noninferiority comparison. Mayo Clinic Proceedings, 86(7), 615-626. https://doi.org/10.4065/mcp.2010. 0681

Van Hecke, O., Austin, S. K., Khan, R. A., Smith, B. H., \& Torrance, N. (2014). Neuropathic pain in the general population: A systematic review of epidemiological studies. Pain, 155(4), 654-662. https://doi.org/10.1016/j.pain.201 3.11 .013

Zilliox, L. A. (2017). Neuropathic Pain. CONTINUUM Lifelong Learning in Neurology, 23(2), 512-532. https://doi.org/10.1212/CON.0000 000000000462 